\title{
O DIREITO COMO
}

\section{MEMÓRIA CULTURAL}

Recebimento do artigo: 08/05/2008

Aprovado em: 17/06/2008

\section{Stephan Kirste}

Alemanha

kirste@jurs.uni-heidelberg.de

\section{Sumário}

Introdução. $1 \mathrm{O}$ conceito de memória cultural. 2 Mecanismos de memórias. 3 A memória do direito. 3.1 Direito consuetudinário e memória cultural. 3.2 A codificação e suas implicações na memória jurídica. 3.3 A estrutura temporal do direito e sua função mnemônica. $4 \mathrm{~A}$ influência do direito na memória cultural. 4.1 O exemplo dos arquivos do Serviço Secreto da Alemanha Oriental. 5 Conclusão.

\section{Resumo}

A memória é geralmente considerada habilidade individual, psicológica. As ciências sociais e culturais investigam estruturas aparentemente análogas na sociedade, denominadas memória coletiva, cultural ou social. O conceito de "memória cultural", especialmente, fornece uma perspectiva integrada e comparativa sobre as técnicas de determinados sistemas sociais no seu

Doutor pela Universidade de Friburgo, 1997. Professor da Univ. Heidelberg. trato com a história. Com raras exceções, o conceito não tem sido recepcionado pela teoria dodireito. Este texto objetivalançarum primeiro olhar sobre a função que o direito tem com respeito à memória. Em primeiro lugar, considerando que, em memórias sociais, lembrar e esquecer baseiam-se em decisão e tais decisões estão abertas a critérios fornecidos pelas leis. Elas podem

* Tradução de João Maurício Adeodato a partir de KIRSTE, Stephan. Der Beitrag des Rechts zum kulturellen Gedächtnis. Archiv für Rechts- und Sozialphilosophie, 94 (2008), Heft 1, S. 47 69, e Law as cultural memory, palestra proferida na Faculdade de Direito do Recife em 07 de junho de 2007. 
evitar, por exemplo, a instrumentalização da memória cultural ${ }^{1}$. Em segundo lugar, se há uma pluralidade de memórias, elas necessitam de coordenação, no sentido de facilitar certas memórias coletivas, mas também de proteger memórias minoritárias ou individuais ${ }^{2}$. Contudo, se a memória é uma função necessária de todos os sistemas sociais, então temos que investigar as estruturas de memória do sistema jurídico como um sistema de normas e também de comunicações.

\section{Palavras-chave}

Direito como memória cultural. Memória como função dos sistemas sociais.

\section{Abstract \\ Memory is mostly considered to be an individual, psychological ability. Social and cultural sciences investigate seemingly analogous structures in society as the collective, cultural or social memory. The concept of "cultural memory" especially provides}

an integrative and comparative perspective of the techniques of certain social systems in their mutual dealing with history. With the rare exceptions the concept has not been received by legal theory. This text aims to shed a first glance on the function that law has concerning the memory. First, since in social memories recalling and forgetting is based on decision, these decisions are open to criteria provided by laws. They may prevent for example the instrumentalization of the cultural memory. Second, if there is a plurality of memories, they need coordination, meaning the facilitation of certain collective memories, but also the protection of minoritarian or individual memories. If, however, memory is a necessary function of all social systems, then we have to investigate the memory structures of the legal system as a system of norms and also of communications as well.

\section{Key words}

Law as cultural memory. Memory as social systems function.

\section{Introdução}

Deixe-me começar com um exemplo quando, em 1989, nos dias finais da República Democrática Alemã, os cidadãos viram fumaça saindo do prédio do quartel-general da polícia secreta (Stasi) e perceberam que parte importante de seu passado estava em perigo de se perder. Funcionários da outrora temida polícia secreta estavam queimando arquivos, gravações e documentos pertinentes a suas investigações ilegais - pelo menos em relação aos parâmetros da idéia de império da lei no Estado de Direito.

1 ASSMANN, Jan. Das kulturelle Gedächtnis, in: Erwägen - Wissen - Ethik 13 (2002), p. 276. $\mathrm{O}$ autor vê a instrumentalização política da memória cultural como um indicador factual da memória coletiva. Se toda memória é procedimental, ela pode ser sujeita à manipulação e necessitar de limites normativos para sua modificação.

2 LANGENOHL, Andreas. Kulturelles Gedächtnis? Soziologische Bedenken (Replik auf Jan Assmann). In: Erwägen - Wissen - Ethik 2 (2002), p. 255-258, p. 257; LANGENOHL, Andreas. Erinnerungskonflikte und Chancen ihrer „Hegung“, in: Soziale Welt 52 (2001), p. 71s. 
Os cidadãos invadiram o quartel-general e tentaram apossar-se desses documentos.

Conseguiram resgatar grande quantidade deles, alguns já em pedaços. Com isso pretendiam assegurar a possibilidade de saber que informações o regime tinha reunido sobre eles, pois, durante o período da República Democrática Alemã, eles nem sequer eram informados sobre o passado pelo qual o regime os responsabilizava quando os colocava na prisão ${ }^{3}$.

Os documentos foram entregues a uma agência recém-fundada. Desde então, dentre outras atribuições, a agência reconstruiu os arquivos danificados, colocou-os em ordem e apoiou publicações sobre as atividades do serviço secreto. Sua tarefa mais importante, porém, é permitir aos antigos cidadãos, cientistas e jornalistas da RDA, dentre outros interessados, acesso aos dados. Esses arquivos tornaram-se fonte importante para a investigação da história da RDA. Logo ficou óbvio que os arquivos também continham dados sobre "ocidentais", cidadãos e especialmente políticos ainda no cargo. A mídia, mas também um comitê de investigação do parlamento alemão, demonstraram interesse, especialmente nos arquivos referentes ao ex-chanceler Helmut Kohl. Em vários processos, Kohl teve sucesso ao impedir acesso e publicação desses dados.

Esse relato, na medida em que revela um problema especificamente alemão, mostra também como a memória individual e a memória social funcionam e podem colidir ${ }^{4}$. Além disso, exemplifica a função do direito no desenvolvimento da memória cultural. Antes de explicar essa tese, o conceito de memória precisa ser colocado. Depois, a função do direito com respeito ao passado será analisada para, finalmente, voltar ao exemplo da Stasi.

\section{O conceito de memória cultural}

A memória é geralmente considerada habilidade individual, psicológica. Desde Maurice Halbwach, as ciências sociais e culturais investigam estruturas aparentemente análogas na sociedade, denominadas memória coletiva, cultural ou social.

O conceito de "memória cultural", especialmente, fornece uma perspectiva integrada e comparativa sobre as técnicas de determinados sistemas sociais no seu

BIRTHLER, Marianne. Ohne Erinnerungskultur kein Selbstbewußtsein. Die Stasiakten und der Umgang mit der eigenen Vergangenheit, in: Vorgänge, 2003, p. 22-30.

4 Para o caso particular, cf. BIRTHLER, Marianne. Ohne Erinnerungskultur kein Selbstbewußtsein. Die Stasiakten und der Umgang mit der eigenen Vergangenheit, in: Vorgänge, 2003, p. 24. Aspectos gerais são discutidos em LANGENOHL, Andreas. Erinnerungskonflikte und Chancen ihrer "Hegung", in: Soziale Welt, 52 (2001), p. 71-92. 
trato com a história ${ }^{5}$. Com raras exceções ${ }^{6}$, o conceito não tem sido recepcionado pela teoria do direito. Essa negligência tem duas razões: de um lado, os próprios estudos culturais mencionados omitem estruturas de memória do direito, embora considerem-no um fenômeno cultural; de outro, porque conceitos da teoria do direito, tais como "tradição", "historicidade", "mudança" ou "continuidade" parecem fornecer fundamentos teóricos suficientes. Então, por que introduzir um novo termo?

Vamos então ao conceito de memória. Em geral, a memória pode ser definida como capacidade de representar informação relevante para o eu de cada um, com base em certas mídias e em uma seleção entre lembrar e esquecer. Essa definição não pressupõe um portador da memória determinado, ela toma a memória como uma função de um sistema. Se nós seguirmos o bem elaborado conceito da lingüista Aleida Assmann e de seu marido, o egiptólogo Jan Assmann, podemos distinguir as memórias individuais, de geração, coletivas e culturais por meio de outros critérios.

Comparada às demais, a memória individual é limitada e fragmentada, constituindo uma perspectiva não transferível e, em seu caráter comunicativo, dependente de estabilização por meio da narração ${ }^{10}$. Omitimos a memória de geração porque ela pode ser conceituada mediante um índice temporal na memória coletiva. $\mathrm{Na}$ visão de Assmann, esta capacidade tem como característica distintiva a artificialidade: entes coletivos supostamente não obtêm memória, mas sim, numa maneira que Nietzsche descreveu em seu conceito de "memória da vontade", fazem-na por meio de símbolos, textos, ritos, imagens, calendários, práticas, associações a locais, monumentos e outras formas simbólicas.

5 Os autores clássicos da sociologia usam o termo apenas de maneira aforística, sem um sentido sistemático. V. OLICK, Jeffrey K.; ROBBINS, Joyce. Social Memory Studies: From "Colective Memory" to the Historical Sociology of Mnemotic Practices, in: Annual Review of Sociology, 24 (1998), p. 105-140, p. 107.

6 LUHMANN, Niklas. Gesellschaftsstruktur und Semantik, Band 4. Studien zur Wissensoziologie der modernen Gesellschaft. Frankfurt a. M.: Suhrkamp, 1999, p. 42 s.; cf. também CONFINO, Alon. Collective Memory and Cultural History: Problems of Method, in: The American Historical Review, 102 (1997), p. 1386-1403, p. 1389.

7 SARAT, Austin; KEARNS, Thomas R. History, Memory, and the Law. Ann Arbor: The University of Michigan Press, 2002; KAHN, Paul W. The Cultural Study of Law Reconstructing Legal Scholarship. Chicago: University of Chicago Press, 1999.

8 KRYGIER, Martin. Law as Tradition, in: Law and Philosophy, 5 (1986), p. 237-262.

9 LLOMPART, José (S. J.). Die Geschichtlichkeit des Rechts im Deutschland der Gegenwart. Frankfurt a. M.: Metzner, 1968; LLOMPART, José (S. J.). Die Geschichtlichkeit der Rechtsprinzipien. Frankfurt a. M.: Klostermann, 1976; KIRSTE, Stephan. Die Zeitlichkeit des positiven Rechts und die Geschichtlichkeit des Rechtsbewußtseins. Momente der Ideengeschichte und Grundzüge einer systematischen Begründung. Berlin:, Duncker \& Humblot, 1998.

10 ENGISCH, Karl. Vom Weltbild des Juristen. Heidelberg: Winter, 1965. 
A memória coletiva é integrada negativamente por delimitação e distinção de outras memórias culturais, criando assim identidades homogêneas. Exemplos são memórias nacionais, suprimindo as memórias coletivas de minorias, pondo em perigo suas identidades. Fora isso, sua integração por meio de tradições e de narrativas produz outras dicotomias: memórias de vítimas e memórias de culpados, memória dos vencidos e memória dos vencedores. Antagônicas são também as atitudes que se seguem a essas distinções: perdoar e esquecer ou memorizar e procurar vingança ou "justiça histórica"11.

$\mathrm{Na}$ visão de Assmann, a memória cultural está situada "acima" da memória coletiva, aparentemente referindo-se a comunidades mais amplas ou a sociedades. Contudo, pretende também diferenciá-la estruturalmente da memória coletiva, que utiliza meios externos para preencher a função memorizadora: artefatos para arquivar dados, livros, filmes e instituições. O potencial dessa memória objetiva é uma perspectiva de longo prazo e uma função mais integradora. Sobre essa base pode-se fazer diferença entre memória de arquivo latente e memória ativa funcional.

É notável, nesse modelo, que não somente os indivíduos apareçam como portadores da memória. Ele foi criticado com base no argumento de que somente indivíduos possuem um cérebro e outras capacidades necessárias à memória. Conseqüentemente, admitir outras memórias pode ser meramente metafórico ou analógico. Essa objeção, contudo, não poderia explicar formas de memória que transcendem o indivíduo, como os monumentos, a linguagem e a lei.

Isso poderia levar ao argumento contrário: considerando seu caráter comunicativo, não é a memória individual um simples reflexo das formas de memória social? Mas isso não explicaria a liberdade de os indivíduos manterem sua memória, mesmo se a memória social pressionar o sentido do esquecimento. Essas objeções podem ser evitadas se distinguirmos, conforme sugerido, a função da memória, o meio de comunicação e o portador da memória. Então a questão é: onde encontramos formas de seleção de certos dados, que estão sendo posteriormente conformados e estabilizados?

No modelo resumido acima, Assmann exagera o aspecto da lembrança. Não há dúvida de que a anamnesis, essa lembrança de experiências anteriores é parte da memória. Mas não é toda a memória. Mesmo essa função não consiste apenas na abertura de algo guardado ${ }^{12}$, mas também numa atividade que influencia esse algo.

\footnotetext{
11 ASSMANN, Aleida. Vier Formen des Gedächtnisses, in: Erwägen - Wissen - Ethik, 13 (2002), p. 183-189.

12 AUGUSTINUS, Aurelius. Bekenntnisse. Mit einer Einleitung von K. Flasch. Übersetzt, mit Anmerkungen versehen und herausgegeben von K. Flasch u. B. Mojsisch. Stuttgart: Reclam, 1989, X, VIII, 12, p. 259, supunha ser a memória um arquivo e pensava na lembrança como uma atividade de selecionar os elementos úteis a partir dele.
} 
A lembrança tem que se concentrar em certos aspectos que serão trazidos à memória. Outros dados podem ser deixados inativos e mesmo ser esquecidos.

A filosofia antiga, especialmente a de Platão e a de filósofos até a Idade Média, ressaltaram a lembrança positivamente e o esquecimento negativamente. Parece que o filósofo místico alemão Master Eckhart é o primeiro a enfatizar o poder catártico do esquecimento, como um meio para trazer a mente de volta ao próprio eu. Kierkegaard segue esta idéia e fala do esquecimento como "um par de tesouras com o qual se elimina tudo o que não pode ser usado" ${ }^{\text {"13. }}$.

O objetivo do poder de esquecer é liberar a ação de limitações. Esse aspecto foi mais desenvolvido por Friedrich Nietzsche em suas Observações Atemporais ${ }^{14}$ : o esquecimento possibilita ao ser humano concentrar-se em si mesmo como base para a criação do espaço livre para a ação. Numa perspectiva sociológica, a dimensão do esquecimento libera - como coloca Niklas Luhmann - "capacidades para processar informações no sentido de abrir o sistema a novas irritações" ${ }^{15}$. Memória não é apenas manter impressões, mas também organizar o acesso aos dados. Essa atividade combina lembrar e esquecer ${ }^{16}$.

A discriminação ativa entre lembrar e esquecer, a capacidade de transformar informação em latência - sem perdê-la completamente - e ativar outros dados, pode explicar o desenvolvimento da especificidade da memória ${ }^{17}$. Sistemas memorizam somente dados relevantes presentemente e deixam o resto para a memória de outros sistemas.

Isso tem duas conseqüências: mais do que a individual, a memória social parece ser capacidade construtiva ou ativa, selecionando informação de acordo com as

13 KIERKEGAARD, Sören. Entweder-Oder. Leipzig: Richter, 1885, p. 232: “O esquecimento é a tesoura com a qual se corta fora o que não se pode utilizar, mas sempre sob a máxima supervisao da lembrança. Esquecer e lembrar-se são por isso idênticos e constituem a identidade artificialmente produzida do ponto de Arquimedes, com o qual se levanta todo o mundo."

14 NIETZSCHE, Friedrich. Unzeitgemäße Betrachtungen II. Vom Nutzen und Nachteil der Historie für das Leben. Werke, Bd. 1, COLLI, G. e MONTINARI, M. (Hrsg.). München: Beck, 1999, p. 243-334.

15 LUHMANN, Niklas. Die Gesellschaft der Gesellschaft. Frankfurt a.M.: Suhrkamp, 1997, p. 579: "A principal função da memória está no esquecimento, em impedir o autobloqueio do sistema por meio de uma cristalização dos resultados de observações anteriores."

16 ESPOSITO, Elena. Soziales Vergessen. Formen und Medien des Gedächtnisses der Gesellschaft. Frankfurt a.M.: Suhrkamp, 2002; ESPOSITO, Elena. Eine Erinnerung an das Vergessen, in: Erwägen - Wissen - Ethik 13 (2002), p. 248 s.: "A memória não é... um depósito mais ou menos seletivo do passado..., mas sim uma reconstrução, em forma de lembranças, que só existem em oposição àquilo que inevitavelmente tem que ser esquecido.”

17 A memória específica produz informação que é temporariamente perdida na comunicação ativa da sociedade, mas pode servir como um potencial para crítica. FRITZSCHE, Peter. An Aesthetics of Loss, in: Erwägen - Wissen - Ethik 13 (2002), p. 251-253, p. 252. 
exigências do respectivo sistema. Capacidade ativa significa ter alternativas. A conseqüência de ter alternativas é a abertura para critérios de escolha e isso resulta na possibilidade de influência normativa, especialmente jurídica, sobre o estabelecimento da memória. Em segundo lugar, se a memória é uma concentração ativa de informação útil para o "eu" - isto é, o respectivo sistema - então essa especialização permite memórias diferentes. Se houver memórias especializadas é mais fácil, e menos perigoso, esquecer mais, sendo assim capaz de relembrar mais informação relevante ${ }^{18}$.

Nenhuma memória poderia então substituir a função de outra. A memória individual é deixada livre da memória social, ainda que se apóie no processo comunicativo para seu desenvolvimento19. Como coloca Michael Stolleis: "Se o juiz encerra um caso está liberado do assunto. Esta é 'sua liberdade" "20. Mas sua decisão não será esquecida pelo sistema jurídico. Na sociedade há uma pluralidade de memórias pessoais e coletivas que traz superposições ou pode competir ${ }^{21}$, mas é primordialmente independente.

Se a unidade entre lembrar e esquecer é central para a constituição do eu, então não há a alternativa de não ter memória. A memória parece ter importante impacto no desenvolvimento da identidade. Experiências individuais e compartilhadas, tradições, ritos, sítios históricos, literatura e assim por diante - todos são pontos de identificação para indivíduos e também sistemas sociais. Os sistemas precisam ter a capacidade de memória para decidir quem eles são, como um ponto de partida de suas operações. Presentismo - uma atitude diante do passado que não aparece apenas em regimes ditatoriais ${ }^{22}$ - torna-se então uma atitude crítica para a coesão

18 ESPOSITO, Elena (2002a): Eine Erinnerung an das Vergessen, in: Erwägen - Wissen - Ethik 13 (2002), p. 248. Isso é facilitado pela moderna mídia de armazenamento, o que prova que mais importante do que a habilidade de lembrar é a habilidade de selecionar e esquecer, de modo a manter a informação relevante.

19 LUHMANN, Niklas. Die Gesellschaft der Gesellschaft. Frankfurt a.M.: Suhrkamp, 1997, p. 583 s. A diferença entre a memória individual e a social deixa o indivíduo livre "para combinar os mesmos temas com memórias muito diferentes e assim, de forma aparentemente acidental, afetar a comunicação social".

20 STOLLEIS, Michael. Der Historiker als Richter - der Richter als Historiker, in: FREI, Norbert; VAN LAAK, Dirk; STOLLEIS, Michael (Hrsg.). Geschichte vor Gericht. Historiker, Richter und die Suche nach Gerechtigkeit. München: C. H. Beck, 2000, p. 173-183, p. 178.

21 Instituições e organizações (igrejas, partidos) também têm suas memórias, pois a opinião pública e os indivíduos pertencem a não apenas uma, mas a muitas delas, e, ao mesmo tempo em que dividem a memória respectiva, também se distinguem dela. Cf. FAULENBACH, Bernd. Lösen sich in der Gegenwart die im 19. Jahrhundert herausgebildeten "kulturellen Gedächtnisse" auf? Zur Anwendbarkeit von Jan Assmanns Theorie auf die neueste Zeit, in: Erwägen - Wissen - Ethik 13 (2002), p. 249-251, p. 250.

22 FAULENBACH, Idem, p. 250; ASSMANN, Jan. Das kulturelle Gedächtnis, in: Erwägen Wissen - Ethik 13 (2002), p. 236. A proteção de feriados religiosos pode ser problema no capitalismo liberal. 
em qualquer sociedade. Um perigo da memória social é sua coesão, a qual constrói a identidade interna mas, em compensação, é externamente excludente, para aqueles que não pertencem ao grupo.

Esses aspectos lançam um primeiro olhar sobre a função que o direito tem com respeito à memória. Em primeiro lugar, considerando que, em memórias sociais, lembrar e esquecer baseiam-se em decisão e tais decisões estão abertas a critérios fornecidos pelas leis. Elas podem evitar, por exemplo, a instrumentalização da memória cultural ${ }^{23}$. Em segundo lugar, se há uma pluralidade de memórias, elas necessitam de coordenação, no sentido de facilitar certas memórias coletivas, mas também de proteger memórias minoritárias ou individuais ${ }^{24}$. Contudo, se a memória é função necessária de todos os sistemas sociais, então temos que investigar as estruturas da memória do sistema jurídico, como um sistema de normas e também de comunicações.

\section{Mecanismos de memórias}

Como funcionam então as memórias? A memória está baseada em mídias muito diferentes, tais como escrita, monumentos, música, poesia, narrações e discursos públicos ou meros artefatos eletrônicos. Arquivar torna-se uma forma cada vez mais importante, não apenas para armazenamento, mas também para organização da informação. Arquivos, contudo, são mídia de memória e não a própria memória, porque eles resultam dos critérios que decidem o que armazenar dentro deles e de outros critérios reguladores do uso da informação.

Para estabilizar o conhecimento, a memória emprega técnicas temporais como repetição, cadência e técnicas visuais, como fez a antiga mnemotécnica com a tópica ou o uso de símbolos. Detalhando suas idéias sobre a memória da vontade, Friedrich Nietzsche enfatiza a importância da dor e do castigo na constituição ou formação da memória ${ }^{25}$. Em todas essas técnicas, a forma parece ser o meio mais

23 ASSMANN, Idem, p. 276. O autor vê a instrumentalização política da memória cultural como um indicador factual da memória coletiva. Se toda memória é procedimental, ela pode ser sujeita à manipulação e necessitar de limites normativos para sua modificação.

24 LANGENOHL, Andreas. Kulturelles Gedächtnis? Soziologische Bedenken (Replik auf Jan Assmann). In: Erwägen - Wissen - Ethik 2 (2002), p. 255-258, p. 257; LANGENOHL, Andreas. Erinnerungskonflikte und Chancen ihrer „Hegung“, in: Soziale Welt 52 (2001), p. $71 \mathrm{~s}$.

25 NIETZSCHE, Friedrich. Jenseits von Gut und Böse / Zur Genealogie der Moral. Werke, Bd. 5, COLLI, G. e MONTINARI, M. (Hrsg.). München: Beck, 1999, p. 295: “Como se faz no animal-homem uma memória? Como se imprime algo nesse entendimento momentâneo, a essa viva aptidão para o esquecimento, de modo que permaneça presente?' Esse antigo problema não foi solucionado com respostas e meios delicados, como se pode imaginar; talvez não haja nada tão temível e monstruoso em toda a pré-história humana do que sua mnemotécnica. 'Imprime-se 
importante para a criação da memória: o amorfo não pode ser lembrado ${ }^{26}$.

O objetivo é estabelecer uma situação ampliada, na qual a pluralidade de eventos pode ocorrer, todos relacionados ao "texto" como a base de comunicações não presenciais ${ }^{27}$. "Cultura" significa a unidade global e mais genérica dessas situações ampliadas. Os "textos culturais" para estabilização de memórias sociais "são todos articulações semânticas ou simbólicas, comunicadas em uma dada sociedade, dentro da moldura de uma situação ampliada" ${ }^{28}$. Assmann considera esses textos vinculantes de duas maneiras: eles contêm comandos normativos para a vida em comum de um povo e vinculam as pessoas criando identidade.

Outro aspecto importante da memória social é a "canonização". O imperador romano Justiniano chamou atenção para seu significado na Antiguidade Clássica. $\mathrm{Na}$ introdução de suas Instituições, começa enfatizando a classificação exaustiva e a sistematização das instituições imperiais e os escritos da antiga jurisprudência. "Depois que isso foi conseguido com sucesso", continua ele,

nós comissionamos pessoas para compor essas instituições sob o poder de nossa autoridade e de acordo com nossas diretivas. Dessa maneira, não se precisa aprender os ensinamentos elementares sobre o direito a partir de velhas histórias, mas se é capaz de deduzi-los de um excelente trabalho imperial, e ouvidos e intelecto não assimilarão nada inútil e errado, mas apenas aquilo que é realmente válido na vida do direito. $^{29}$

A canonização do direito na concepção de Justiniano tem o papel de (1.) coletar o material jurídico, (2.) selecionar o relevante e separá-lo das regras irrelevantes, e (3.) colocá-lo em ordem, formando assim a base para a educação e também a prática do direito. Isso mostra bem como a canonização é um importante aspecto da memória de um sistema social.

algo a fogo para que permaneça na memória: somente o que não cessa de causar dor permanece na memória' ... Quanto pior 'de memória' era a humanidade, mais temível sempre é o aspecto dos usos que esta faz daquela; a dureza das leis penais, particularmente, dá uma medida de quanto esforço a humanidade teve que fazer para chegar à vitória sobre o esquecimento e manter presentes umas tantas exigências primitivas de convivência social para esses escravos momentâneos da emoção e do apetite."

26 ASSMANN, Jan. Das kulturelle Gedächtnis, in: Erwägen - Wissen - Ethik 13 (2002), p. 240 s. e 273.

27 Idem, p. 242.

28 Idem, p. 243.

29 Corpus Iuris Civilis, Inst., Einleitung, p. 3. Corpus Iuris Civilis. Text und Übersetzung. Institutionen. Hrsg. u. übers. v. BEHRENDS, O.; KNÜTTEL, R.; KUPISCH, B. 2. Aufl. Heidelberg: C.F. Müller, 1997. 


\section{1 Direito consuetudinário e memória cultural}

Esse aspecto ilumina os pré-requisitos da memória do sistema jurídico e também seu impacto em outras memórias sociais. A possibilidade de influenciar, contudo, depende da memória e esta, por sua vez, da autonomia temporal do direito. O mecanismo subjacente será mostrado em pequeno resumo sobre a distinção entre direito consuetudinário e codificado.

Em sua forma costumeira, o direito é dependente da memória cultural. Uma visão clássica do direito como costume provém de Friedrich Carl von Savigny, que escreve, em seu famoso Vom Beruf unserer Zeit für Gesetzgebung und Wissenschaft. "Assim, conclui-se que todo direito emerge da forma que o uso prevalente chama de costumeira, significando que ele é produzido por costumes, crenças e, finalmente, pela doutrina, sempre por forças internas e silenciosas, não pelo arbítrio de um legislador" ${ }^{30}$. Em termos mais técnicos, o direito costumeiro é considerado válido sem uma legislação formal por causa do uso (longa consuetudo) e da convicção de necessidade de sua observância (opinio necessitatis/opinio juris).

Historicamente, o direito costumeiro pode ser mais antigo do que o codificado, embora não seja o mais antigo. Em sua forma original, o grego agraphoi nomoi tinha a estrutura das "boas e velhas leis", as quais, por sua longevidade, adquiriam caráter quase divino. Sua estrutura temporal era uma fixação quase absoluta a um passado indeterminado. Em comparação com isso, o direito costumeiro é um modelo histórico de direito: com os costumes sempre mudando, o próprio direito torna-se variável.

No direito germânico medieval, os costumes jurídicos eram referidos na linguagem comum do povo, não no latim técnico e especializado, e tinham seu lugar na "coisa", o locus fori dessa tradição. A circunscrição a um local é característica central desse direito. Memorizá-los significava conectá-los a determinados lugares. A efetiva validade desses costumes jurídicos, portanto, dependia de memória topográfica e rítmica, também elementos importantes da antiga mnemotécnica retórica. A transmissão oral desses costumes jurídicos permanecia ligada à consciência individual dos portadores da memória e evitava qualquer forma independente da memória de um sistema ${ }^{31}$.

\footnotetext{
$\overline{30}$ SAVIGNY, Friedrich Carl von. Vom Beruf unserer Zeit für Gesetzgebung und Wissenschaft. Heidelberg, 1814, p. 105.

31 LUHMANN, Niklas. Die Gesellschaft der Gesellschaft. Frankfurt a.M.: Suhrkamp, 1997, p. 216 s. e 250.
} 
A inserção de costumes jurídicos na cultura oral tem implicações importantes em sua temporalidade: o direito não pode ser antecipação ou estruturação do futuro, porque isso implicaria um curso linear do tempo. Como diz Gerhard Dilcher: "Uma cultura oral tende a se concentrar mais em identidades de níveis temporais - significando a presença do passado - e não pode nem pretende ter um controle racional de permanência e mudança." ${ }^{32}$. Basicamente, presente e futuro não são separados, pois o presente é inteligível somente por causa das conquistas mnemônicas duradouras do costume.

Isso muda com o aparecimento de documentos escritos: não somente a longevidade e a autoridade da fonte individual de memória são importantes, mas a confiabilidade tem que ser atestada no momento presente e pode ser provada com base em outros documentos ${ }^{33}$. Finalmente, o Sachsenspiegel de Eike von Repchow, como uma primeira forma de reduzir a termo o direito germânico, considerava-se um "espelho" (Spiegel) que pretendia registrar as normas tradicionais de seus ancestrais ${ }^{34}$.

Isso não significava, contudo, que o espelho era apenas um artefato técnico. Nos passos de Gracián, Repchow colecionou somente os costumes genuínos, omitindo outras tradições. Assim, o registro tinha conteúdo normativo, não era apenas auxílio mnemônico. Nessa nova forma, os costumes jurídicos eram retirados de seus portadores originais e daí esclarecidos, ordenados e tornados facilmente transferíveis. O processo de abstração subjacente era óbvio quando os costumes eram recolhidos por agricultores querelantes e depois ordenados em "registros".

Em alguns casos, esses registros eram escritos em latim, numa linguagem que os agricultores não compreendiam. Dessa maneira, o senhor feudal poderia potencialmente usá-los contra eles ${ }^{35}$. Aqueles que tinham sido costumes dependentes da memória individual dos agricultores foram transformados em nova mídia, que permitia não somente - talvez - uma lembrança mais confiável, mas também tornava possível o esquecimento. A memória jurídica tornou-se mais seletiva e específica em sua separação da memória individual.

32 DILCHER, Gerhard. Gewohnheitsrecht und Rechtsgewohnheiten. Berlin: Duncker \& Humblot, 1992., p. 51.

33 KRAUSE, Hermann (1958): Dauer und Vergänglichkeit im mittelalterlichen Recht, in: Zeitschrift für Rechtsgeschichte - Germanistische Abteilung 75 (1958), S. 206-251, p. 215.

34 „Dit recht hebbe ek selve nicht irdacht / it hebbet van aldere an unsik gebracht / unse guden vorevaren,“ apud KROESCHELL, Karl. Deutsche Rechtsgeschichte. Band 1: bis 1250. Opladen: Westdeutscher Verlag, 1999, p. 248.

35 KUCHENBUCH, Ludolf. Verrechtlichung von Erinnerung im Medium der Schrift (9. Jahrhundert), in: ASSMANN, Aleida; HARTH, Dietrich. Mnemosyne - Formen und Funktionen der kulturellen Erinnerung. Frankfurt a. M.: Fischer, 1993, p. 36-47, p. 40 s. 
Finalmente, profissionais da Escola de Direito de Bolonha assumiram cultivar a memória jurídica. A memória jurídica separou-se da memória cultural geral porque foi capaz de estabelecer critérios próprios de seletividade para o que deveria ser lembrado e o que poderia ser esquecido, deixado a uma tradição rural que não tinha qualquer relevância jurídica. As leis escritas permitem a abstração da situação concreta, na qual os sujeitos presentes se comunicam ${ }^{36}$. A origem do texto perde relevância para determinação de seu conteúdo, deixando mais espaço para a interpretação, se a forma textual não for precisa o bastante para excluir essa possibilidade $^{37}$. A liberdade, ampliada no trato com o texto legal, pode ser usada para sistematizar determinações isoladas.

Em um ambiente que - pelo menos na Europa central - é dominado pelo direito codificado, o direito costumeiro pode ter alguma significação. Problemas fáticos, contudo, mesmo para o sociólogo Eugen Ehrlich, limitam a alta reputação que tinha o direito costumeiro. Primeiro, numa sociedade que muda rapidamente, não há tempo suficiente para que os costumes ganhem a confiabilidade que pode ser a base para a validade legal. O segundo problema diz respeito a sua seletividade. Como afirma Theodor Geiger:

O costume não é uma fonte de validade legal porque há muitos costumes que não são obrigatórios e outros que o são extra-legalmente; e aqueles que são legalmente obrigatórios não têm essa qualidade em virtude de costumes, mas sim de outros fatores. ${ }^{38}$

E, se eles são finalmente aceitos como legalmente obrigatórios não têm a vantagem de um texto-norma confiável, como enfatizou Friedrich Müller. Assim, Max Weber estava certo em concluir que a rejeição do direito costumeiro é característica da idéia de codificação ${ }^{39}$. Resumindo, o direito costumeiro perdeu sua função de memória jurídica para a mídia mais especializada, mais apropriada: o direito codificado.

36 LUHMANN,Niklas. GesellschaftsstrukturundSemantik, Band4. Studienzur Wissensoziologie der modernen Gesellschaft. Frankfurt a. M.: Suhrkamp, 1999, p. 37 s.; LUHMANN, Niklas. Die Gesellschaft der Gesellschaft. Frankfurt a.M.: Suhrkamp, 1997, p. 257 e 266: : "O efeito da escrita está no desacoplamento espacial e temporal de comunicação e entendimento e na enorme explosão de possibilidades de conexões que por meio dela se apresentam."

37 Sobre a textualidade do direito, cf. MORLOK, Martin. Der Text hinter dem Text - Intertextualität im Recht, in: BLANKENAGEL, Alexander; PERNICE, Ingolf; SCHULZE-FIELITZ, Helmuth. Verfassung im Diskurs der Welt - Liber Amicorum für Peter Häberle zum siebzigsten Geburtstag. Tübingen: Mohr Siebeck, 2004, p, 93-136, p. 93 s.

38 GEIGER, Theodor. Vorstudien zu einer Soziologie des Rechts. Mit einer Einleitung und internationalen Bibliographie zur Rechtssoziologie von Paul Trappe. Neuwied: Luchterhand, 1964, p. 171 e 183.

39 WEBER, Max. Wirtschaft und Gesellschaft, 5. Aufl. Tübingen: J.C.B. Mohr, 1980, p. 494. 


\subsection{A codificação e suas implicações na memória jurídica}

$\mathrm{Na}$ Europa continental, o direito codificado teve sucesso. Conceitos jurídicos em forma de direito costumeiro foram substituídos, em sua maior parte, por sistemas normativos com conceitos orientados para o futuro, especialmente como princípios constitucionais. Mas a novidade de seu conteúdo não é o aspecto principal. Hegel afirma, corretamente, que uma codificação legal pode ser distinguida de uma coleção de leis ou costumes, não pelo conteúdo - que pode ou não ser um costume - mas por sua forma. A forma da codificação é a recepção consciente que ordena esses comandos sob a forma geral de princípios jurídicos ${ }^{40}$.

A antecipação que o direito faz do futuro é o fundamento da conduta jurídica. O direito feito pelo juiz e a dogmática jurídica substituem a origem costumeira do direito. Aquele "que encontra o julgamento" (Urteilsfinder), na condição de portador da memória jurídica no direito germânico, passou suas tarefas para um juiz profissional, treinado ${ }^{41}$. A dogmática tem precisamente uma função de memória do sistema jurídico: ela desenvolve estruturas de significados, acúmulo de experiências e seleciona e mantém latentes os argumentos não escolhidos pelo sistema central, que assim são movidos para a periferia ${ }^{42}$. A dogmática jurídica está em um constante trabalho de separar lembrança de esquecimento. O sucesso dessas interpretações não é dependente de um passado difuso, de uma transmissão de eventos (Überlief erungsgeschehen, Gadamer) aos quais o intérprete tem que se alinhar. O passado ao qual o trabalhador jurídico (Müller) se reporta tem um começo temporal claro e é dependente de seu momento presente.

O direito constitucional, contudo, tende a produzir uma crescente independência entre interpretação e texto. Assim a teoria constitucional e a jurisdição das cortes constitucionais não apenas permitem a memória constitucional extra-legal, como também uma reintegração final entre as memórias jurídica e cultural. Isso também poderia ser novamente explicado pela tese de que a função da constituição é um "acoplamento estrutural" dos sistemas jurídico e político ${ }^{43}$.

40 HEGEL, Georg Wilhelm Friedrich. Philosophie des Rechts: Grundlinien der Philosophie des Rechts oder Naturrecht und Staatswissenschaft im Grundrisse. Mit Hegels eigenhändigen Notizen in seinem Handexemplar und den mündlichen Zusätzen. Hrsg. und eingeleitet v. Helmut Reichelt. Frankfurt a. M. - Berlin - Wien: Uhlstein, 1972, \211A, p. 187.

${ }^{41}$ KROESCHELL, Karl. Deutsche Rechtsgeschichte. Band 1: bis 1250. Opladen: Westdeutscher Verlag, 1999, p. 40 e 95.

42 ESSER, Josef. Grundsatz und Norm in der richterlichen Fortbildung des Privatrechts. Rechtsvergleichende Beiträge zur Rechtsquellen- und Interpretationslehre. Tübingen: Mohr, 1974, p. 108 s.

43 LUHMANN, Niklas. Verfassung als evolutionäre Errungenschaft, in: Rechtshistorisches Journal 9 (1990), p. 176-220. 
Paul W. Kahn descreveu o processo de mudança de atitude em relação à Constituição, por parte da Suprema Corte norte-americana e da teoria do direito constitucional, em quatro modelos ${ }^{44}$.

A abordagem original da Constituição dos Estados Unidos era o que Kahn denominou o modelo do fazer: o ato de construir a moldura ocorreu em situação de crise, a qual foi experimentada num momento de catarse, produzindo uma interrupção no círculo de paixões e de partidos e permitindo uma visão esclarecida da política ${ }^{45}$. "Para o fundador da Constituição, o tempo político é um futuro a ser moldado; para o continuador, o tempo político é um passado a ser preservado."46

Aqui surge nova atitude: memória. $\mathrm{O}$ que Kahn, em segundo lugar, chama o modelo da manutenção é um modelo mnemônico. Em rituais como discursos em ocasiões históricas (de que são exemplos os de Abraham Lincoln no Liceu e em Gettysburg) e em mitos, a dependência do presente em relação ao passado é louvada para manter vivas e fazer crescer as sementes que os fundadores plantaram, no intuito de assegurar um desenvolvimento orgânico.

Depois da Guerra Civil, outro momento de crise, a Constituição passou a ser vista como um trabalho feito pelo homem, incompleto em comparação com a verdadeira Constituição, a "Constituição não escrita". Era o pensamento do direito natural sendo introduzido na interpretação constitucional. Não era o texto constitucional "letra morta" sem o espírito dessas normas? Na perspectiva desse terceiro modelo, o modelo do crescimento, o texto da Constituição servia apenas como "material bruto", um veículo para o crescimento moral, e posteriormente, numa "visão realista", para melhoria social do povo.

O modelo do crescimento, finalmente, possibilitou o modelo da comunidade, após a Segunda Guerra Mundial. Preocupados com a dificuldade contramajoritária (Bickel), conceitos como consenso e discurso fizeram a normatividade do direito dependente de uma aceitação no presente.

Isso mostra um desenvolvimento que, começando com a memória da moldura, faz com que, tanto mais se modifica a situação social, mais unidade seja produzida, uma unidade entre lembrança e esquecimento que abre espaço para a ação presente, mas também para questionar as limitações do passado, que permanecem. O estágio final é de presentismo, no qual a memória quase que perdeu sua função - quase,

${ }_{44}$ KAHN, Paul W. Legitimacy and History. New Haven and London: Yale University Press, 1992; KAHN, Paul W. The Cultural Study of Law - Reconstructing Legal Scholarship. Chicago: University of Chicago Press, 1999, p. 48 s.

45 KAHN, Paul W. Legitimacy and History. New Haven and London: Yale University Press, 1992, p. 16.

46. Idem, 1992, p. 59. 
porque senão um novo processo de emolduramento teria que começar. Essa atitude para com as constituições faz com que desapareça sua forma normativa ${ }^{47}$.

O aspecto principal da visão de Kahn sobre esse desenvolvimento da teoria constitucional é a dificuldade de manter a seletividade da memória jurídica, já que os textos legais visam a enrijecê-la. Na realização social dessa tarefa, eles dependem da apresentação de seus comandos na interpretação e na decisão. Essa reapresentação tende a ficar independente, chegando a um presentismo que questiona a função mnemônica e normativa do direito.

\subsection{A estrutura temporal do direito e sua função mnemônica}

O direito objetiva enrijecer o futuro, como dito. Pretende interferir no curso dos eventos. Assim, o passado não é apenas recepcionado nos elementos fáticos da norma, mas já é a um passado selecionado que o direito se refere. E, também nas conseqüências jurídicas, o direito não aceita a relação causal natural, mas a substitui por uma conseqüência intencional ${ }^{48}$. A seleção feita pela codificação significa que o passado é parcialmente lembrado e parcialmente esquecido e deve importar para o futuro apenas sob essa forma.

Dentro do sistema jurídico, a presença do passado depende de uma seleção. A normatividade da lei significa essa vinculação do futuro com base em um passado selecionado ${ }^{49}$. A lei decompõe o passado, confere e avalia sua relevância e a necessidade de mantê-lo. Isso pode servir a demandas para proteger confiança ou à necessidade de construir arranjos temporais para suavizar as conseqüências das mudanças na lei.

Essa abordagem seletiva do passado seria vã, contudo, se a lei fosse arbitrariamente modificável. Sua estabilidade dependeria então da vontade dos detentores do poder, sujeitando a lei às mudanças culturais. No mesmo sentido, a mudança legal também precisa ser submetida a normas. Elementos centrais do direito codificado

\footnotetext{
47 KAHN, Paul W. Legitimacy and History. New Haven and London: Yale University Press, 1992, p. 172: "A autoridade do direito, incluindo o direito constitucional, ,e inconsistente com o igualitarismo da comunidade do discurso". E na p. 214: "O modelo da comunidade surge quando o sujeito toma consciência de que o objeto conhecido é produto de uma interpretação, que não existe qualquer significado apartado do ato discursivo que dá significado à expressão".

48 KELSEN, Hans. Reine Rechtslehre. 2. Aufl. Deuticke, Wien, 1960.

49 KIRSTE, Stephan. Die Zeitlichkeit des positiven Rechts und die Geschichtlichkeit des Rechtsbewußtseins. Momente der Ideengeschichte und Grundzüge einer systematischen Begründung. Berlin: Duncker \& Humblot, 1998; KIRSTE, Stephan. Constituição como início do direito positivo: a estrutura temporal das constituições, trad. João Mauricio Adeodato, in: Anuário dos Cursos de Pós-Graduação em Direito (da Faculdade de Direito do Recife), $\mathrm{n}^{\circ}$ 13. Recife: Ed. UFPE, p. 111-165.
} 
são as regras secundárias como fonte de validade para as regras primárias. Essas regras secundárias não somente estabilizam as primárias, mas também garantem as regras de modificação. Isso significa que até o passado, recepcionado seletivamente, não dura para sempre, mas - pelo menos potencialmente - apenas por algum tempo, até poder ser esquecido pelo direito. Essas regras de mudança são a base da autonomia temporal da lei em relação à alteração social. Elas constituem também os pilares da influência da lei sobre a memória social. Elas protegem a lei de mudança involuntária e assim criam um presente estendido que Assmann considera objetivo primordial de qualquer memória.

Mediante sua função de esquecimento, o direito pode harmonizar uma sociedade no que diz respeito a uma história ditatorial ou totalitária de um Estado e aos crimes cometidos naquela época. Ou ele pode apoiar coercitivamente a justiça para as vítimas da ditadura, da segregação ou da discriminação racial ou sexual. Ele pode proteger o direito de se conduzir de acordo com os próprios costumes, isto é, como direito de minoria, promover a "justiça cultural"50. Hans Kelsen está certo em dizer que a validade dos costumes como direito depende de seu reconhecimento legal ${ }^{51}$ : a partir de sua forma criadora, o costume passou a ser o conteúdo protegido pelo direito.

\section{A influência do direito na memória cultural}

Um último aspecto ilumina mais adiante a função do direito para a memória cultural em geral. Conforme dito antes, com base em seleção (canonização), em ritualização (Rudolf von Jhering: $A$ luta pelo direito) e em conformação, a memória é a unidade de esquecimento e a lembrança, a capacidade ativa de indivíduos, assim como de sistemas sociais. Mediante a canonização de normas válidas e a conformação de sua mudança, mas também por meio da seleção de evidência relevante em julgamentos e da força legal de decisões judiciais, o direito mostra a mesma estrutura. É assim possível falar de memória jurídica.

Por causa de suas estruturas, que garantem autonomia temporal, o direito positivo pode transformar sua dependência dos costumes em costumes dependentes do

50 FIKENTSCHER, Wolfgang. The Sense of Justice and the Concept of Cultural Justice: Views from Law and Anthropology, in: American Behavioral Scientist 34 (1991), p. 314-334.

51 KELSEN, Hans. Reine Rechtslehre. 2. Aufl. Deuticke, Wien, 1960, p. 9: "Devido ao fato de o costume ser constituído por atos de conduta humana, também as normas produzidas pelo costume são estabelecidas por atos de conduta humana e, portanto, normas postas, isto é, normas positivas, tal como as normas que constituem o sentido subjetivo de atos legislativos. Por meio do costume tanto podem ser produzidas normas morais como normas jurídicas. As normas jurídicas são normas produzidas pelo costume, se a constituição da comunidade põe o costume - um costume qualificado de determinada maneira - como fato criador do direito.” 
direito. Por isso o sistema de memória do direito adquire relevância social: ele não apenas regula sua própria memória, mas também influencia outras memórias sociais expressas em tradições, costumes, rituais etc. Algumas de suas normas, inclusive, visam a influenciar diretamente a memória cultural.

\subsection{O exemplo dos arquivos do Serviço Secreto da Alemanha Oriental}

Tudo isso agora será finalmente explicado por nosso exemplo. Quando recuperaram os arquivos, as vítimas de espionagem estavam ansiosas por recolher o material necessário para adquirir consciência de seu passado, de maneira a construir sua memória. A polícia secreta fez o melhor possível para fazer o passado ser esquecido. Numa ação coletiva, os cidadãos se apossaram dos documentos e ajudaram a si mesmos e ao público no sentido de recuperar soberania sobre o conhecimento de seu passado ${ }^{52}$. O material que pôde ser salvo, base social daquele regime, não estava ainda preparado para a tarefa. Teria que ser reconstruído e posto em ordem. A memória individual sobre a real extensão da supressão de liberdade, sob o regime totalitário da República Democrática Alemã, dependia da ação coletiva.

Mas aí os arquivos foram colocados sob os cuidados do Estado. Permitindo acesso aos arquivos, o Estado tinha que respeitar direitos subjetivos daquelas pessoas às quais os arquivos se referiam. O desejo dos acusados de esquecer o passado tinha diminuído a quantidade de material. Mas não apenas os antigos funcionários do Serviço Secreto queriam deixar o passado ser esquecido; os arquivos continham informação muito pessoal sobre vítimas no leste e também sobre cidadãos da República Federal da Alemanha, como foi o caso do ex-chanceler Helmut Kohl. Nesses conflitos de memória, o direito tinha que equilibrar os interesses jurídicos afetados. Os direitos constitucionais de personalidade, garantidos na Alemanha pelo art. $1^{\circ}$ (dignidade humana) e pelo art. $2^{\circ}$ (liberdade geral de ação) da Lei Fundamental, permitem a cada pessoa decidir por si mesma sobre a imagem que quer ter em público.

A partir desse direito básico, o Tribunal Constitucional Federal deduziu um direito especial à auto-determinação informacional. Ambos lutam pelo esquecimento ${ }^{53}$. Por outro lado, as liberdades de conhecimento, de imprensa etc., protegidas pelo art. $5^{\circ}$ da Lei Fundamental, não podem ter impedido seu trabalho em busca de informação. Uma comissão de inquérito do parlamento alemão tem também competência para obter informação, com base no art. 44 da mesma Lei. Ao sopesar esses direi-

52 BIRTHLER, Marianne. Ohne Erinnerungskultur kein Selbstbewußtsein. Die Stasiakten und der Umgang mit der eigenen Vergangenheit, in: Vorgänge, 2003, p. 25.

53 Um aspecto diferente da dignidade humana garante a proteção da personalidade após a morte, isto é, a imagem que uma pessoa apresentou contra a crítica posterior. 
tos, tem-se que ter presente que as agências da Alemanha Ocidental jamais teriam permissão para obter esses dados de inteligência por causa da proteção à privacidade (arts. 10 e 13). É claro que a memória cultural das atividades do antigo Serviço Secreto da República Democrática Alemã e de seu impacto no sistema supressivo de liberdade é altamente dependente de decisões legais.

A partir da questão de quais documentos podem ser guardados, os que podem ser entregues ao público em geral, mídia, cientistas, e quais aqueles que podem ser entregues somente às próprias vítimas e de que maneira (anônima ou abertamente) o direito seleciona entre a possibilidade de lembrança e - pelo menos temporariamente - de esquecimento (dirigindo-os à latência dos arquivos). Há também uma transformação da memória: primeiro encontramos a vontade individual de conseguir informação para sua memória. Depois, a ação popular constrói memória coletiva contra as tentativas dos antigos oficiais, no sentido de fazer esquecer a história da supressão de liberdades. Finalmente, a memória passa a ser institucionalizada em arquivos e o direito começa a regular o acesso aos arquivos.

O direito tem a função de harmonizar as diferentes memórias, repita-se, de equilibrar lembrança e esquecimento ${ }^{54}$. Esta é a função que transcende o sistema jurídico. A memória do sistema jurídico influencia a memória de outros sistemas sociais, ou seja, influencia a memória cultural como um todo.

O exemplo provém da história alemã e de sua ordem legal, mas os problemas por trás dele são problemas de transições legais em geral. Numa mudança dos valores básicos dos sistemas jurídicos, o novo sistema tem que decidir sobre como lidar com seu passado e com pessoas que cometeram "crimes" que não eram criminalizados no antigo regime e com a informação obtida nesses sistemas.

De qualquer modo, precisa decidir como o presente vai se comportar em relação ao passado. Pode proteger a memória - como fizeram os alemães, punindo a Auschwitzlüge -, pode usar a memória para punir os "criminosos" que, sob o antigo regime, furtaram-se ao castigo, modelando suas leis nesse sentido, ou pode harmonizar a sociedade, analisando o passado, mas evitando punir - como fizeram os sul-africanos, em suas "comissões da verdade", e o Brasil, com sua anistia. A legislação, em primeiro lugar - e não a jurisdição - provê um fórum para obter critérios gerais para o esquecimento e a lembrança, dessa maneira influenciando a memória cultural geral.

$54 \quad$ SCHLINK, Bernhard. Die Bewältigung der Vergangenheit durch Recht, in: KÖNIG, Helmut (Hrsg.) Vergangenheitsbewältigung am Ende des zwanzigsten Jahrhunderts. Opladen: Westdeutscher Verlag, 1998, p. 441. 


\section{Conclusão}

Durante o tempo de validade de suas normas, o direito se arvora ser atemporal. No presente estendido, antes de sua próxima mudança formalizada, ele provê os critérios para as distinções entre ações legais e ilegais. O elemento fático da norma permite a representação seletiva do passado e os elementos conseqüentes da norma regulam sua importância. Já que a mudança de normas legais é restringida pelas regras de mudança, o passado estendido não depende diretamente de outras forças sociais.

Especialmente a memória cultural em geral, que foi historicamente responsável pelo direito em forma de costumes jurídicos, perdeu sua importância. Ao contrário, com base nessa autonomia, o direito é capaz de estabelecer uma memória jurídica, que é função principal da dogmática jurídica. Ele também pode influenciar a memória cultural, harmonizando os conflitos entre memória individual e memória coletiva, desde que esses conflitos possam ser legalmente reformulados.

Os costumes jurídicos passam a referir-se à lei e não são mais a forma de sua validade. Falar de memória jurídica influenciando a memória social não é apenas uma expressão metafórica: a memória é a unidade de esquecimento e lembrança, com o objetivo de selecionar e estabilizar, e com base em mecanismos tais como ritualização, canonização e conformação. Essas funções podem ser encontradas na memória individual assim como na memória coletiva. O direito como memória cultural não significa que o direito é apenas memória, mas que ele tem um impacto importante na memória cultural. 